\title{
Bernardo Ribas Carli: o poder político da família
}

\author{
Daniel Bruce Lane ${ }^{1}$
}

Matheus Donizeti Klepscke Ribeiro ${ }^{2}$

- Enviado em 28/08/2017

- Aprovado em 08/12/2017

\section{Introdução}

Muitas famílias possuem tradição de estarem por gerações no poder da máquina estatal, e Ribas é um destes sobrenomes que aparece com grande influência no Paraná.

A exemplo de tal questão, tem-se atualmente o jovem parlamentar Bernardo Ribas Carli, eleito para as legislaturas de 2010-2014 e 2014-2018 da Assembleia Legislativa do Paraná (ALEP).

Vários outros membros dessa família atuaram há décadas na política do estado, como por exemplo: Miguel Ribeiro Ribas (1722-1795), capitão da cavalaria auxiliar, que foi da governança de Curitiba; Brasílio Ribas, nascido em Ponta Grossa em 1870, presidente da câmara de Ponta Grossa, deputado estadual e prefeito de Ponta Grossa durante 16 anos; Brigadeiro Manoel Ferreira Ribas, deputado provincial. (OLIVEIRA, 2000).

Todavia é importante destacar Manoel Ribas, que é um dos maiores expoentes da família Ribas, já que ele governou o Paraná por 13 anos. De 1932 a 1934 como interventor indicado por Getúlio Vargas, de 1935 a 1937 como governador eleito e ainda entre 1937 a 1945 novamente como interventor indicado por Getúlio. (O ESTADO, 2015).

Manoel Ribas era um típico herdeiro do poder das famílias históricas do processo de formação da sociedade paranaense. Descendia de famílias presentes na fundação de Curitiba e com longa preponderância política desde o século XVII. Era neto do Brigadeiro Manoel Ferreira Ribas, descendente dos fundadores de Pitangui-Ponta Grossa. O grupo de parentesco dos descendentes de Manoel Ribas e de sua irmã, Maria da Conceição Ribas Vauthier (...) abrange o seguinte conjunto de nomes de tradição política no Paraná:

\footnotetext{
${ }_{1}$ Graduando em Engenahria de Controle e Automação pela UTFPR. E-mail: danielblane98@gmail.com 2 Técnico em Eletroeletrônica e Graduando em Engenharia de Controle e Automação pela UTFPR. E-mail: matheus_dkr@yahoo.com.br 
Lupion, Fontana, Macedo, Oliveira Franco, Hauer, Erichsen, Maciel, Lacerda e Guimarães. (OLIVEIRA, 1997).

Manoel Ribas nasceu em Ponta Grossa, Paraná, no dia 08 de março de 1873. Em 1897 mudouse para Santa Maria, Rio Grande Sul, para organizar a Cooperativa dos Empregados da Viação Férrea do Rio Grande do Sul, na qual realizou uma boa administração e ganhou notoriedade, se tornando prefeito desta cidade em 1927, iniciando assim sua carreira política.

Em 1932, quando assumiu pela primeira vez o governo do estado do Paraná, o presidente Getúlio Vargas buscou Manoel em Santa Maria para fazê-lo assumir o cargo vago após a renúncia do general Mário Tourinho, isso porque Vargas o considerava como uma solução para os conflitos políticos que estavam instaurados.

No dia 6 de novembro de 1945 Manoel Ribas deixou o governo do estado, logo após a queda de Getúlio, e poucos meses depois, em 28 de janeiro de 1946, veio a falecer. (MANOEL, 2017).

Manoel Ribas teve uma grande carreira pública e hoje muitos descendentes Ribas estão espalhados nos poderes executivo, legislativo e judiciário brasileiro, a exemplo disso pode-se citar Luis Fernando Ribas Carli e seu filho Bernardo Ribas Carli, que são figuras políticas influentes.

\section{Biografias da família Ribas Carli}

Luis Fernando Ribas Carli, filho de Ivo Carli e Iná Ribas Carli, nasceu em Guarapuava, centro-sul do Paraná, em 9 de outubro de 1949. A família do pai é de origem italiana, sem atuação política no Brasil; enquanto que pelo lado da mãe, o sobrenome Ribas já carregava um grande patrimônio político, pois a mãe de Luis Fernando é descendente de Manoel Ribas, vindo de um ramo familiar que começa pelo capitão Miguel Rodrigues Ribas no Paraná em 1694. Mais especificamente, a mãe de Luis Fernando, Iná, é bisneta de Anna Benedita do Sacramento Ribas que é irmã do brigadeiro Manoel Ferreira Ribas, avô do interventor Manoel Ribas. (FAMÍLIA, 2017).

Em entrevista à doutora Solange Fiúza ele fala sobre a origem das famílias paterna e materna:

[...] minha mãe é descendente desse pessoal. A família do meu pai é que chegou mais tarde, meu avô paterno era italiano. A família do meu pai chegou em Guarapuava em 1918, meu pai tinha 4 ou 5 anos de idade.

Agora, a família da minha mãe é toda daqui. Atrás desse Ribas está Siqueira, Ferreira, Maciel, Rocha Loures, Alves. São as famílias ligadas.

Ribas é da minha mãe e o Carli do meu pai (FIÚZA, 2016, p.149). 
Em 1970 se mudou para Curitiba iniciando os estudos em Farmácia e Bioquímica na Universidade Federal do Paraná. Em 1975 retornou à sua cidade natal onde abriu um laboratório de análises clínicas. (LUIS,2017).

No ano de 1981 se filiou ao Partido do Movimento Democrático Brasileiro (PMDB) e logo em 1983 se tornou o secretário geral do partido em Guarapuava. (LUIS, 2017). Ingressou no Partido Democrático Trabalhista (PDT) em 1986 e concorreu como deputado estadual para o Paraná nas eleições, ficando apenas como suplente. (DEPUTADOS, 2017). Em 1989 concorreu e ganhou as eleições para prefeitura de Guarapuava. Foi eleito para deputado federal em 1994, porém, pouco tempo após assumir o cargo, acabou se licenciando para se tornar chefe da Casa Civil do estado do Paraná. Em 1996 voltou ao posto de deputado, e neste mesmo ano assume também a posição de vice-líder do PDT. Cumpriu um mandato na Assembleia Legislativa Estadual entre 1999 e 2002, foi reeleito em 2002 e se afastou da ALEP em 2004 para concorrer à prefeitura de Guarapuava. Então se tornou prefeito e foi reeleito em 2008. (LUIS,2017).

A partir de 2013, com o fim do mandato de prefeito, passou a se dedicar à administração da empresa de sua propriedade, do ramo de chapas de madeira compensada. (FIÚZA, 2016, p.149). Luis Fernando também recebe uma aposentadoria de $\mathrm{R} \$ 14.600,54$ do estado do Paraná referente ao cargo de perito oficial. (REMUNERAÇÃO, 2017).

Fernando casou-se com Ana Rita Slaviero Guimarães, herdeira das importantes famílias Slaviero e Guimarães, com a qual tem dois filhos: Luiz Fernando Ribas Carli Filho e Bernardo Ribas Carli. (LUIS, 2017).

Luiz Fernando Ribas Carli Filho foi eleito para deputado estadual pelo PSB em 2006 aos 26 anos. Enquanto exerceu o cargo ele apresentou projetos de lei ligados principalmente à saúde e educação. (PROJETOS, 2017).

Na madrugada do dia 7 de maio de 2009, o então deputado se envolveu em um acidente de trânsito, motivo de sua renúncia, que matou dois jovens enquanto dirigia alcoolizado e em alta velocidade. Este caso ganhou repercussão nacional e, apesar disso, não foi julgado até hoje. (FERNANDO, 2009). No dia 11 de maio deste ano o ministro Gilmar Mendes retirou da pauta do STF um habeas corpus da defesa, não tendo data prevista para a análise do recurso, por isso, na prática, o processo foi impedido de seguir adiante para poder chegar a uma conclusão. (TSE, 2017).

Bernardo Ribas Carli nasceu 26 de Fevereiro de 1986, na cidade de Guarapuava. (ELEIÇÕES, 2014). É formado em administração de empresas e é, atualmente, deputado estadual em sua segunda legislatura consecutiva pelo PSDB. (DEPUTADOS, 2017). Em 2010, quando concorreu pela primeira vez, obteve 33645 votos e em 2014 foi eleito com 55481, demonstrando que, enquanto deputado, conseguiu aumentar seu eleitorado através da construção e manutenção de sua imagem. (ESTATíSTICAS, 2017). 
Entre suas ações recentes na política, de maneira geral, pode-se destacar a entrega de viatura para a Polícia Militar de Pinhão, a entrega de viatura para os Bombeiros de Laranjeiras do Sul e uma vistoria nas obras do Hospital Regional, em Guarapuava. (BERNARDO, 2017). Enquanto que na ALEP ele atuou através de projetos de lei voltados principalmente para a área da saúde, e ainda fez inúmeros requerimentos de votos de pesar. (PROJETOS, 2017).

Atualmente Bernardo Carli faz parte de algumas comissões permanentes, isto é, organizações entre integrantes da ALEP que possuem caráter técnico-legislativo, sendo responsáveis por determinada área do interesse coletivo. Desde maio de 2011, a ALEP conta com 26 Comissões Permanentes. Sendo as cinco das quais ele participa: a Comissão Permanente de Ciência, Tecnologia e Ensino Superior; a de Esportes; a de Fiscalização da ALEP e Assuntos Municipais; a de Revisão e Consolidação Legislativa e a do Mercosul e Assuntos Internacionais. (COMISSÕES, 2017).

Atua também em várias Frentes Parlamentares, que são associações entre deputados de diferentes partidos visando discutir um tema específico, a fim de encontrar soluções ou aprimorar a legislação sobre determinado assunto. Bernardo Carli tem participação em nove delas, a Frente Parlamentar Anticorrupção; a da Educação Física e Atividades Físicas; a das Energias Renováveis; a de Apoio à Cadeia Produtiva da Uva; a de Apoio à Cadeia Produtiva do Leite; a de Apoio ao Comércio; a em Apoio à Indústria Paranaense de Bebidas; a em Defesa da Cadeia Produtiva da Reciclagem; a em Defesa das Universidades Estaduais do Paraná e a Mista da Crise Agrária do Município de Quedas do Iguaçu. (FRENTES, 2017).

Contudo o deputado é ligado a vários escândalos, em 2011 teve o mandato cassado por gasto ilícito de recursos na campanha, entretanto, poucos dias após a decisão do Tribunal Regional Eleitoral do Paraná, o ministro do TSE suspendeu a cassação. (TSE, 2011). Em 2016 foi condenado novamente por caixa dois e uso de documentos falsos para esconder a prática ilegal, porém, com recursos da defesa, até hoje ele não cumpriu a pena aplicada. (JUSTIÇA, 2017).

\section{Construção da imagem da família de Bernardo Ribas Carli}

A pesquisadora doutora Solange Fiúza mostra em sua tese de doutorado que a família tem grande interesse em deixar sua marca na cidade e faz isso através da divulgação das "conquistas" obtidas por eles por meio da máquina pública.

Ana Rita Slaviero foi presidente do Programa do Voluntariado Paranaense (Provopar) durante as gestões municipais de seu marido Fernando Carli. (FIÚZA, 2016, p.149).

Uma definição do que é o Provopar é encontrada no site da própria instituição: 
O Provopar Estadual é uma associação civil, com personalidade jurídica de direito privado, sem fins econômicos e lucrativos, com a finalidade de assistência social, educacional, beneficente, cultural, ambiental, saúde e geração de renda.

Nossa Missão é: Contribuir para a melhoria da qualidade de vida, cidadania e humanização da sociedade paranaense.

Nossa Visão é: Ser referência nacional em desenvolvimento humano e promoção da autonomia, através de ações de qualificação profissional e geração de renda.

Valores: Atuação fundamentada nos princípios da legalidade, impessoalidade, moralidade, publicidade e eficiência, sem discriminação de raça, cor, gênero e religião. (INSTITUCIONAL, 2017).

O Provopar é uma instituição mista do poder público e privado o que confere a ele regulamentação diferente das instituições públicas. Geralmente são as primeiras-damas que dirigem a instituição, dando assim manutenção ao poder familiar no estado. (FIÚZA, 2016, p.149). Também se utilizam da divulgação de investimentos realizados em serviços públicos relacionando isso a imagem dos integrantes da família. Na figura 1 um investimento de 50 milhões de reais no Hospital Regional de Guarapuava é relacionado aos deputados estaduais Bernardo Ribas Carli e Artagão Júnior. A figura 2 é um outdoor que foi espalhado por Guarapuava relacionando Bernardo Ribas Carli ao Hospital Regional. A construção deste hospital foi defendida pelo deputado estadual e, desde então, ele relaciona a obra à sua imagem. (HOSPITAL, 2017).

Figura 1- Outdoor que liga deputados ao Hospital Regional

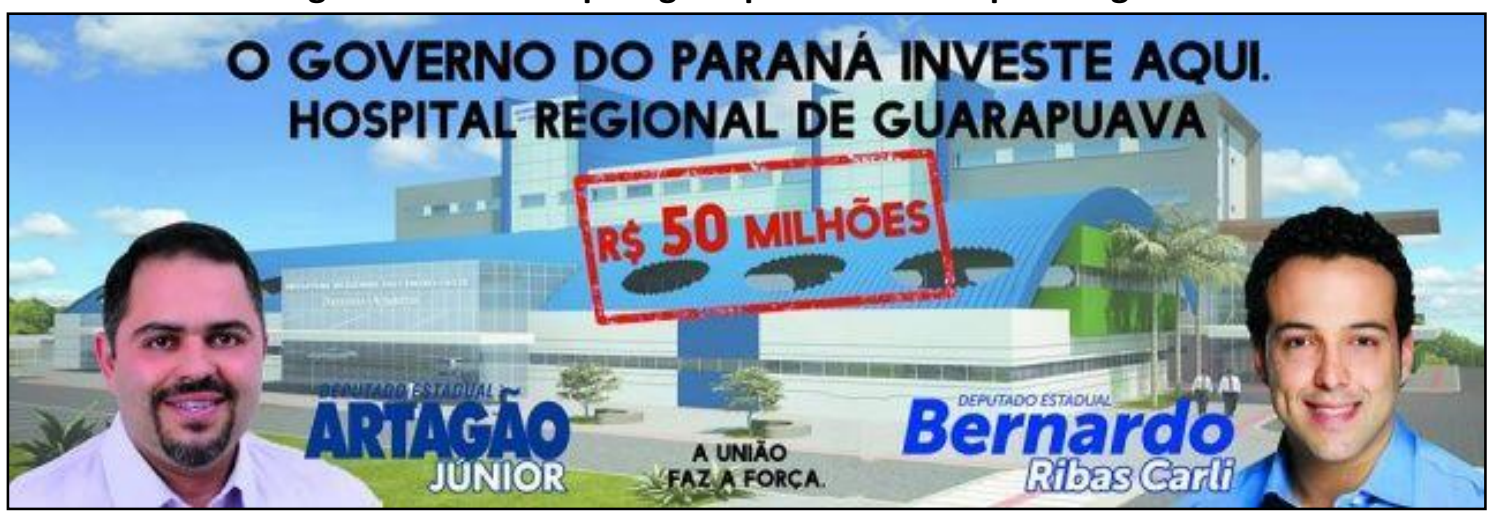

Fonte: Rede Sul de notícias ${ }^{3}$ agao_jr.htm >. Acesso em 19/06/2017. 
Figura 2- Outdoor relaciona Hospital Regional a Bernardo.

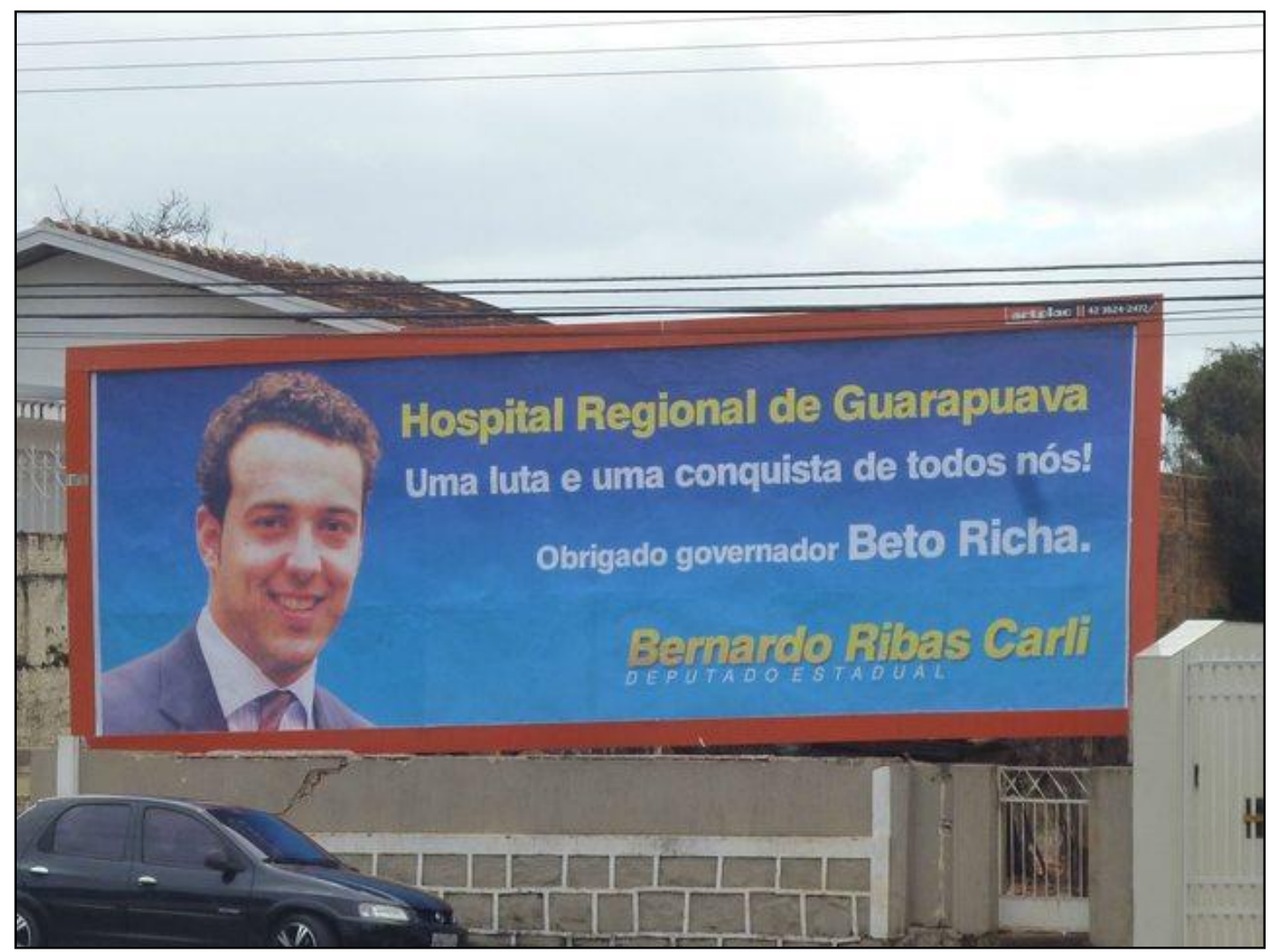

Fonte: Fórum de discussões na internet ${ }^{4}$

\section{Relações de poder no âmbito particular}

A família Ribas Carli, pela sua influência na política, conseguiu se relacionar, através de casamentos, com várias outras famílias importantes no cenário político paranaense. Como os Slaviero, Guimarães, Miró, entre outros. Isso é um costume entre as famílias de classes dominantes, que formam laços matrimoniais para manter a influência na sociedade. Como pode-se observar na fala do autor Ricardo Costa de Oliveira, que enfatiza a importância da família no ambiente político brasileiro:

Família ainda importa. As estruturas de parentesco formam parte da realidade social e política brasileira no século XXI. Redes familiares controlam partidos políticos, controlam o centro do poder executivo e formam redes atravessando o poder legislativo com parlamentares hereditários, sempre se renovando pelas gerações. (OLIVEIRA, 2012, p. 13).

\footnotetext{
${ }_{4}$ Disponível em <http://www.skyscrapercity.com/showthread.php?t=1454158\&page=256 >. Acesso em 19/06/2017.
} 
Um exemplo de um membro de uma família poderosa, que possui parentesco com os Ribas, é Plauto Miró Guimarães Filho. Ele é irmão de Ana Rita Slaviero Guimarães Carli, que casou com um Fernando Ribas Carli.

Plauto Miró Guimarães Filho nasceu em Ponta Grossa em 20 de julho de 1963. Em 1990, ele se candidatou para o cargo de deputado estadual e recebeu a maior votação em Ponta Grossa, o que demonstra a influência da família na região dos Campos Gerais. Muito provavelmente porque era filho de Plauto Miró Guimarães, que foi prefeito de Ponta Grossa. Desde então ele manteve o cargo até os dias de hoje, sendo que já está no sétimo mandato como deputado estadual e ainda está exercendo pela terceira vez o cargo de primeiro secretário da ALEP. Plauto Miró Guimarães Filho faz parte do DEM (Democratas), partido ao qual está filiado desde o início de sua carreira política. Implantou o curso de medicina da Universidade Estadual de Ponta Grossa, juntamente com o do governador Jaime Lerner, em 2001. O que, novamente, demonstra o poder político que exercia na região, por meio do seu cargo público. Plauto Miró Guimarães Filho só conseguiu ter tanta influência na política, muito provavelmente, porque, além de ter sido filho de Plauto Miró Guimarães, era de uma família com muita tradição e atuação política no estado do Panará. (PLAUTO, 2017).

O doutor em Sociologia Alessandro Cavassin Alves demonstra em seu artigo a importância desses laços familiares. Ele destaca que nas biografias de Plauto Miró Guimarães Filho e de seu sobrinho Bernardo Ribas Carli apresenta-se que, desde a infância deles, a política fazia parte do cotidiano da família. Os filhos acompanhavam o pai ou o avô nas atividades públicas, e nos eventos, tanto de caráter público quanto privado. Consequentemente, devido a presença de um político na família, conseguia-se algum emprego público, assim os cargos eram passados para a descendência. O que, de acordo com o autor, representa a produção antroponômica, isto é, a formação do ser humano segundo a classe social em que nasceu. (ALVES, 2017).

\section{Relações de poder no âmbito público}

Como se não bastasse, a família Ribas Carli não se relacionou apenas através de casamentos com as outras famílias relevantes, mas também por meio da política. Podemos citar o exemplo de Flávio Carvalho Guimarães, avô de Plauto Miró Guimarães Filho, e filho de pioneiros da região de Ponta Grossa. (FLÁVIO, 2017). Flávio Carvalho Guimarães, que nasceu em Ponta Grossa no dia 21 de abril de 1891, exerceu advocacia e, posteriormente, ingressou na política. Ocupou cargos na administração estadual, como o de Secretário da Fazenda, quando Manoel Ribas era interventor no Paraná. (FGV, 2017). 
Flávio Guimarães além de ser advogado e ter atuado na administração de Manoel Ribas, participou, após o fim do Estado Novo, da articulação do PSD (Partido Social Democrata), juntamente com vários outros membros de famílias tradicionais do Paraná. De uma forma geral nos estados brasileiros, o PSD agrupou os interventores federais, os integrantes mais importantes da máquina administrativa, tanto federal quanto estadual, além de alguns membros vindos da burguesia e da classe média urbana.

Nesse contexto, no Paraná o PSD foi organizado pelo interventor Manoel Ribas e por integrantes dos altos escalões da máquina administrativa estadual. Entre estes estavam os irmãos Flávio Guimarães, Alô Guimarães e Acyr Guimarães, filhos do general Teodorico Gonçalves Guimarães, que pertenciam a uma família bastante tradicional do Paraná. (BATISTELLA, 2015).

Os irmãos Guimarães eram descendentes de Manoel Antonio Guimarães, mais conhecido como Visconde de Nácar. (OLIVEIRA, 2007).

Isso significou uma forte relação de poder entre a família Ribas com um grande expoente da política paranaense. E, de modo geral, demonstra como Manoel Ribas se relacionou com atores políticos, integrantes da elite econômica, membros das famílias tradicionais, de sua época. Por meio de parcerias, cooperações, indicações, nomeações, entre outras formas, foi possível manter esse grupo no poder público. Proporcionando, desse modo, o crescimento econômico e de influência desse grupo na sociedade paranaense.

\section{Considerações Finais}

Com base nisso, buscou-se compreender as relações de poder da família Ribas Carli no cenário político paranaense. Notou-se como os membros atuam na esfera do poder público, utilizando-se dos cargos administrativos, e como ainda exercem poder na esfera privada, através de relações com a classe economicamente dominante. Percebe-se como essa família atua no setor político, econômico e social, em conjunto com as demais famílias da classe dominante. Conclui-se que a grande importância da família tradicional Ribas Carli e o modo pelo qual eles influenciaram, e continuam influenciando, o cenário político e econômico do Paraná, ocorreu devido as relações de poder, tanto na esfera privada quanto na pública, perpetuando a atuação da família tradicional no Estado. Esse poder pode ser exemplificado nas figuras de Bernardo e seu irmão Fernando, dois jovens que, logo após a graduação, foram eleitos deputados na Assembleia Legislativa do Paraná, deixando clara a influência exercida sobre o eleitorado e mostrando que o poder sempre se concentra na mão de poucos. 


\section{Referências}

ALVES, Alessandro Cavassin. A Produção Antroponômica para a Política: Casos no Paraná, Brasil. Revista Núcleo de Estudos Paranaenses, página 136. 2017. Disponível em: < http://revistas.ufpr.br/nep/article/view/54327/33047 >. Acesso em 14/08/2017.

BATISTELLA, Alessandro. A gênese e os anos iniciais do Partido Trabalhista Brasileiro no Paraná. Disponível em: < http://www.uel.br/revistas/uel/index.php/antiteses/article/viewFile/18028/16589 >. Acesso em 10/06/17.

BERNARDO CARLI. Assembleia Legislativa do Paraná. Disponível em: < http://www.alep.pr.gov.br/hotsites/bernardo-carli/ >. Acesso em 07/08/2017.

COMISSÕES da Assembleia Legislativa do Paraná. Disponível em: < http://www.alep.pr.gov.br/atividade parlamentar/comissoes >. Acesso em 14/08/2017.

DEPUTADOS ALEP. Assembleia Legislativa do Paraná. Disponível em: < http://www.alep.pr.gov.br/deputados >. Acesso em 30/05/2017.

ELEIÇÕES de 2014. Bernardo Ribas Carli. Disponível em: < https://www.eleicoes2014.com.br/bernardoribas-carli// > . Acesso em 14/08/2017.

ESTATÍSTICAS Eleitorais. TSE. Disponível em $:<$ http://www.tse.jus.br/eleicoes/estatisticas/estatisticaseleitorais-anos-anteriores>. Acesso em 17/08/2017.

FAMÍLIA RIBAS. Douglas Ribas Busse. Disponível em: < http://www4.netpar.com.br/doubusse/Ribas.htm >. Acesso em 26/07/2017.

FERNANDO RIBAS CARLI PEDE RENÚNCIA do cargo de deputado. DCI. 29 mai. 2009. Disponível em: < http://www.dci.com.br/politica/fernando-ribas-carli-pede-renuncia-do-cargo-de-deputado-id189931.html >. Acesso em 30/05/2017.

FGV. Verbete biográfico de Flávio Guimarães. Disponível em: < http://www.fgv.br/cpdoc/acervo/dicionarios/verbete-biografico/flavio-carvalho-guimaraes $>$. Acesso em 10/06/2017.

FIÚZA, Solange Cristina Rodrigues. Políticas Sociais, Famílias e Poder em Guarapuava-PR. 2016. Tese (Doutorado em Serviço Social e Política Social). Universidade Estadual de Londrina. Londrina, 2016.

FLÁVIO CARVALHO GUIMARÃES. Disponível em: http://www.histedbr.fe.unicamp.br/navegando/glossario/verb b flavio carvalho guimaraes.htm >. Acesso em 10/06/2017.

FRENTES PARLAMENTARES. Assembleia Legislativa do Paraná. Disponível em: < http://www.alep.pr.gov.br/atividade parlamentar/frentes parlamentares e blocos tematicos $>$. Acesso em 14/08/2017.

HOSPITAL REGIONAL. Bernardo Ribas Carli. Disponível em < http://www.bernardoribascarli.com.br/?s=hospital+regional >. Acesso em 18/06/2017.

INSTITUCIONAL Provopar. Provopar estadual. Disponível em: < www.provoparestadual.org.br/modules/conteudo/conteudo.php?conteudo=1 >.Acesso em 10/06/2017. 
JUSTIÇA DETERMINA QUE DEPUTADO CONDENADO comece a cumprir pena.G1 Paraná. 15 mar. 2017. Disponível em:< http://g1.globo.com/pr/parana/noticia/2017/03/deputado-bernardo-carli-deve-cumprirprisao-domiciliar-determina-justica.html >. Acesso em 03/06/2017.

LUIS FERNANDO RIBAS CARLI. Acervo FGV CPDOC. Disponível em: < http://www.fgv.br/cpdoc/acervo/dicionarios/verbete-biografico/luis-fernando-ribas-carli $>$. Acesso em 22/05/2017.

MANOEL RIBAS. Casa Civil do Paraná. Disponível em :< http://www.casacivil.pr.gov.br/modules/conteudo/conteudo.php?conteudo=50 $>$. Acesso em 19/06/2017

"O ESTAdO COMEÇOU COM MANOEL RIBAS". Gazeta do Povo. 11 set. 2015. Disponível em: < http://www.gazetadopovo.com.br/vida-e-cidadania/historia/o-estado-comecou-com-manoel-ribas-

2z144gc9c4rpy7g971x46jhzq >. Acesso em 31/05/2017.

OLIVEIRA, Ricardo Costa de. Famílias, poder e riqueza: redes políticas no Paraná, 2007. Disponível em: < http://www.scielo.br/scielo.php?script=sci arttext\&pid=S1517-45222007000200008>. Acesso em 10/06/17.

OLIVEIRA, Ricardo Costa de. Na Teia do Nepotismo: sociologia política das relações de parentesco e poder político no Paraná e no Brasil, 2012. Curitiba: Ed. Insight.

OLIVEIRA, Ricardo Costa de. Notas sobre a Política Paranaense no Período de 1930 a 1945. Revista de Sociologia e Política. 1997, n.09.

OLIVEIRA, Ricardo Costa de. O silêncio das genealogias: classe dominante e estado no Paraná. 2000. Tese (Doutorado). Universidade Estadual de Campinas. Campinas, 2000.

PLAUTO MIRÓ. Disponível em: < http://www.alep.pr.gov.br/deputados/perfil/50-plauto-miro >. Acesso em 10/06/2017.

PROJETO. Assembleia Legislativa do Paraná. Disponível em: < http://www.alep.pr.gov.br/web/pesquisa projetos/pesquisa projetos.php >. Acesso em 07/08/2017.

REMUNERAÇÃO. Portal da Transparência PR. mai. 2017. Disponível em : < http://www.transparencia.pr.gov.br/pte/pages/pessoal/remuneracoes/exibir remuneracao?windowld=52 $\underline{0}>$. Acesso em 08/06/2017.

TSE suspende decisão e deputado cassado no Paraná fica no cargo. G1 Paraná. 26 out. 2011. Disponível em: < http://g1.globo.com/pr/parana/noticia/2011/10/tse-suspende-decisao-e-deputado-cassado-no-paranafica-no-cargo.html?keepThis=true\&TB iframe=true\&height $=650 \&$ width $=850 \&$ caption $=$ G1 $>$. Acesso em 03/06/2017. 